\title{
Dynamic Psycho-Linguistics: Impact of the Social Interaction System in the Individual Psycholinguistic Prototype
}

\author{
Silva Ibrahimi \& Elisabeta Kafia \\ Albanian University, Department of Psychology, Tirana, ALBANIA \\ Vera Ostreni Halili \\ Albanian University, Department of Medical Sciences, Tirana, ALBANIA \\ Ervin Ibrahimi \\ Security Council and Health Adviser, ITALY
}

Received: 2 May 2020 - Accepted: 1 September 2020 - Published Online: 27 September 2020

\section{Abstract}

Speaking is a cognitive-motor activity apparently simple, which differentiates men from other animals and is made possible by a vast network of cerebral, cortical and subcortical structures. Language implies the relationship of the human being to his world while Psycholinguistics is the dynamic language process that leads to a mutual connection with the world external and with the other, which is other than self. In the history of Albanian psycho-pedagogical thinking there are evidences that reveal the efforts and contributions to understand and interpret the phenomena and problems directly related to the development and education of students of different school ages. The discussion of complex linguistic topics, communication and relationships is related not only to the exhaustion of the definition, but also the ability to take into consideration the circumstances that make them a social-ethnic reference system with the contribution of main references such as linguistic psychology, philosophy of language, linguistics and semiotics, cognitive level analysis and phenomenological aspects in a daily dimension, but also in the form of meanings, concept of reciprocity, social connotation and the dynamic process in the whole.

Keywords: psycholinguistics, communication, psycho-pedagogical thinking, formation of psycho-linguistic construct.

\section{Introduction}

In their endeavors to understand human identity, specialists of psychology and sociology have used different approaches and viewpoints. Their arguments range from the purely intrapsychic representation and macro-social views to the identification of similar processes and terminologies (Gecas et al., 1995; House, 1977). Searching for a stable identity status is one of the most significant approaches of the personality study in the last three decades (Marcia, 1966). The big sources of identity vary in degrees of significance: the most tangible resources appear in the individual's behaviors and affiliations, while the least tangible resources build our personality

(C) Authors. Terms and conditions of Creative Commons Attribution 4.0 International (CC BY 4.0) apply. Correspondence: Silva Ibrahimi, Albanian University, Faculty of Social Sciences, Department of Psychology and Research Center, Tirana, ALBANIA. E-mail: silva.ibrahimi@yahoo.it. 
traits and features. Severe personality pathologies live on a continuum with normal personality. In both representative cases, the preservation of the reality-testing ability is seen. While in normal personality, functionality is adapted and flexible, in the personality pathologies there is rigidity and maladaptation. Our personality traits are partly created by the defenses we use in an automatic unconscious mode and repeatedly under different circumstances. Flexibility and adaptive function of a normal personality reflect the flexible nature of defensive operationalization of a healthy and matured personality. On the other hand, rigidity that characterizes the levels of a pathologic personality reflect the non-affiliation of mechanisms and operations of defense. Individuals with a pathologic personality are generally based on defensive mechanisms of repression and splitting (distortion of image in the mental representations) what constitute the basic features of a "neurotic level" of the personality treated in this study. It is precisely the relative stability and the non-affiliation of neurotic defenses that are attributed to the process of development of identity which maintains the layer of rigidity in the pathologic personality.

In personality pathologies, the maladaptive personality traits may appear as inhibitors of the normal behavior "inhibitory behavioral pattern" or as an extension of certain behaviors "reactive behavioral patterns". In most individuals these patterns are both present. In the case of inhibitory personality traits there is viewed a lack of behavioral patterns that may be suitable for a certain situation. In the reactive personality trait, we encounter behavioral patterns that are not necessarily needed for certain situations.

The seven elements of Personality Organization, when four sub forms are treated in an independent way from the escalating evaluation, involve:

(1) Integrity, which implies the ability of the person to view self in a stable, complex and accurate way;

(2) Object Relations, the ability to maintain intimate, stable and satisfying relationships;

(3) Affect Tolerance, the ability to experience the full range of age-expected emotions;

(4) Affect Regulation, flexibility in using coping strategies;

(5) Superego Integration, the ability to use a consistent and mature moral sensibility;

(6) Reality Testing, the ability to appreciate conventional notions of what is realistic;

(7) Ego Resilience, the ability to respond to and recover from stress resources.

Evidences supporting Personality Organization are rooted in Freudian thought, distinguishing from "primitive" or "pre-oedipal" types to "the more integrative and oedipal" of psychopathology. Depending on psychopathology types, there is an implication of different developmental levels of psychopathology. Authors (Kernberg, Caligor, 2005, and McWilliams 1994- 2011) in their meta-analytical studies, have instrumentalized these distinctions and outlined some core features in determining Personality Organization level (Caligor \& Clarkin, 2010; Kernberg \& Caligor, 2005; McWilliams, 1994).

Other studies by Koelen and colleagues suggest that the level of Personality Organization is connected to treatment outcomes and would be the only important predictor either in the pathological course or in response to treatment (Koelen et al., 2012). A difference between the approach of Personality Organization and diagnostic approach DSM and ICD is that the latters do not clarify a casual relation between personality structure and personality disorders.

In her studies, Nancy McWilliams (2011) rationed that the describing axis and Personality Organization level are independent from one-another. Each form of personality pathology might be manifested in different levels of Personality Organization. Differently from the first psychodynamic line researchers, another researcher introduced a Model of the Two-Polarities 
of the Prototypal Organization, a model that bridges the approaches of diagnosis and treatment in the field of psychodynamic classification. In congruence with theoretical approaches to personality disorders, impairment in the level of self and others, Blatt argued both in the descriptive and theoretical viewpoint, that personality issues are characterized initially by difficulties in attachment and difficulties with self-definition that are set in this two-dimensional continuum which he treated as a Two-Polarity Model (Livesley, 2008; Skodol \& Bender, 2009). The model proposed by Blatt in 2008, argues that relations and self-definition are the two fundamental psychological dimensions that create the theoretical matrix for the understanding processes of personality development; variety of normal personality organization; concepts of creation of psychopathology and the integration of therapeutic action mechanisms. A well-functioning personality, according to him involves the balance of development in interpersonal relation and self-definition. Thus, the mature levels of relationship facilitate development of a stable identity, autonomy and self-understanding that influence to integrated interpersonal relations. Throughout development, traumatic experiences and biological predisposition may create distortions in the developmental lines of individuals and the neglect of relations with others. Referring to the access of Prototype described in this study research, psychopathologic issues may be thought as Prototypes in the two-dimensional model. Prototype of each individual in different stages of development reflects unique means (prototypes) of dealing with the balance of relationship and self-definition, ranging from "normal personality function" to "full symptomatic issues and levels of personality disorders" (Blatt \& Shichman, 1983; McWilliams, 1994). Personality Prototypes are composed by multidimensional and hierarchic structures and represent an entirety of descriptions rather than the simple ones of anxiety, fear, despair etc. Prototypes have an abstract nature as they do not constitute specific categories. Moreover, the quantity of prototypical modes for conflict resolution which can be used by an individual is limited. Boundaries between prototypes are breached which allows individual to use features from different prototypes. In the clinical setting, the spectrum of prototypes that constitute a personality may affect personality development in the form of synergistic interactions of experiences of relationships and self-definition, experiences of closeness and splitting, similarities and unsuitableness and in the consolidation of these interactions as to the principle of "chain" (Safran, Muran \& Eubanks-Carter, 2011; Safran, Muran, Samstag \& Steven, 2002). As the philosophical postulate in the Thematic of Dasein argues: My being is the center focus of existence. We are always related by and related to "our being". It is a vital parameter for us. It is just this being to whom I am concern that relates my possible ways for being. Existence is therefore a stand beyond self-possibilities (Heidegger, 1962).

2. Classification of mental categories through the Psychodynamic Diagnostic Manual (PDM) and the relation of psycholinguistics to it

In the psychodynamic perspective the achievement of a stable and positive comprehension of self and the establishing of satisfying and long-lasting relationship are probably the two fundamental tasks of the individual development.

PDM classifies mental health in two great areas:

(a) Personality Patterns (Axis-P);

(b) Mental Functioning (Axis-M).

The study of the degree of personality organization or personality disorder severity is on the basis of PDM.

The manual is based on current neuroscience, treatment outcome and empirical research which have shown that patterns of emotional, social and behavioral functioning involve a great area of fields interacting together. Studies emphasize the significance of analysis and 
interpretation of the wholeness of emotional and social patterns. Researchers as Blatt, Auerbach, Zuroff, Shahar, Norcross (2002), and Wampold have concluded that the nature of the psychotherapeutic relationship altogether with operating aspects of mind and brain, predicts more outcomes than any specific treatment approach. The nature and range of predictions is in the focus of patterned organizations in the Psychodynamic Diagnostic Manual. PDM treats the entirety of human development: adults, adolescents, children and toddlers. The adult assessment part upon which we have enabled the present study, begins with the adult personality. P-Axis of Personality Patterns and Disorders is placed first in the PDM system as the collected data and their symptoms could not be understand or treated without a depth comprehension on the personality features of the individual. P-Axis considers two areas with a range from a healthy personality (lack of a personality disorder) to a neurotic level of personality disorder. Levels of personality organization (healthy, neurotic, borderline and psychotic) are defined by the assessment of the individual capacities. These capacities includes: identity maturation, ability for stable satisfying relationships, affects tolerance and regulation, moral reasoning, reality testing and the ability to respond to and recover from stress. After determining the entire level of personality organization, we consider the $\mathrm{P}$-Axis personality patterns (which may be adaptive and cause minimum if any impairment) or into a more pervasive personality disorders (which repeatedly cause pain to self or others). Then, the PDM P-Axis considers each personality disorder as their temperamental, thematic, affective, cognitive and defense patterns. The core preoccupation or concern is manipulating or being manipulated. The primary effects of this personality are rage and envy. Characteristic pathogenic belief about self is "I can do everything". Characteristic pathogenic belief about others is "All are selfish, manipulative and dishonest". The manual classifies a depressive personality disorder with subtype of introjective (self-critic), analytic (high reactivity to loss and rejection) and with a converse manifestation; the hypomaniacal personality disorder (high energy, counter-depressive, fear from closeness etc.). PDM also suggests treatment when there are enough evidences. Introjective type responds better to interpretations and insight whereas the analytic type responds better to the present therapeutic-social relationship. Based in these grand prerogatives researchers from the Sapienza University of Rome, created a list with 19 Prototype Disorders in psychoanalysis related to four foundations of personality. Authors integrated these categories in the Psychodiagnostic Chart that assess personality in four basic elements: (1) healthy, (2) neurotic, (3) borderline, and (4) psychotic (Gordon \& Bornstein 2012; Gordon \& Stoffey, 2014).

The second dimension of PDM, Mental Functioning M-Axis, gives a detailed picture of the abilities that contribute to the individual personality and a degree of the overall psychological health or disturbances. M-Axis abilities include: the capacity for regulation, attention and learning; the capacity for relationships (including depth, range, and consistency); the quality of internal experience (level of confidence and self-regard); the capacity for affective experience, expression and communication; the level of defensive patterns; the capacity to form internal representations; the capacity for differentiation and integration; the self-observing capacities (psychological mentalities) and the capacity for internal standards and ideals, that represents the sense of morality. Each of the described capacities was translated into specific statements in the present study. A normal identity is associated with a consistent experience of time and space of self and the Significant Other and with the capacity to assess attributes and internal experiences in depth, complexity and wholeness. This identity is also associated to the capacity of the individual for investing in time on his professional, intellectual and creative concerns. The dynamism is routed according to values, opinions, tastes and beliefs of the individual. Individuals with a pathology in clinical identity appear with an obvious concern in the conception of experiences of self and the world. The clinical and pathological identity is followed by a fragmentarization and instability of understanding self and significant others experiences in time and space. The subjective experience (Axis-S) for self and others is often poor, with lack of depth, superficial and polarized. Tastes, opinions and values are not linear, taken by others around 
but they could easily be shifted. An individual with identity pathologies have a lack in the capacity of understanding others and cannot react to the social issues that surround him or her. Despite the appearance of this pathological identity form in DSM as Borderline Personality Disorder, a range of identity pathologies characterize the majority of severe personality disorders. Clinical setting sees the individual with an identity pathology as associated with high level of treatments withdrawn, impairment of self-reflecting capacities, difficulties to maintain therapeutic alliance, tendency to concrete plans for reality testing and tendency to impulsive actions.

In its expressive form of the pre-conscious, language is the entity that link thoughts and external and internal interaction. Our language structures are necessarily linked to the psychodynamic energy of personality structures and inter-personal abilities of each single personality. The basic function of language, according to psycholinguistic studies, is not the correctness that can be one of the many purposes for what people talk about, but achieving any truly energetic exchange that comes from mutual cross-materialization. We communicate not only because we speak the same language, but also by acting on symbols and their meanings, keep the communication channels open that allow us to develop the state of psychic conversation and mediation. The use of words is an action and interaction, not only when we create and carry words, but also when we remember them in our minds and when we immerse in our thoughts on internal dialogues. Humbolt (2000) expanded his study of the social dimension aspects of language, based on the variety of purposes and functions expressed by the language.

He identified six language functions as follows:

- Referential: discourse refers to something accurate and essential to the information that contains the message;

- Emotional (or expressive): discourse highlights an inherent state of mind, emotions, feelings, identity;

- Fatigue or contact: discourse points to the continuity of communication;

- Imperative: discourse conveys an order;

- Metalinguistic: discourse serves to define other signs such as the use of language for describing Self and the independent cognitive structures;

- Aesthetic: discourse draws attention to how words are used, communicating mainly through their form.

The mediating function of language connects the $E g o$ to the world, or human beings within the material and immaterial world. Representing an object in order to become a concept must be objective, but the process of objectification is realized only through the mediation of the language and the latter is formed only within the word. In fact, the ego is not in an abstract and transcendent individual, but in a concrete member of a collective that is defined in relation to the other (Gazillo et al., 2014). Therefore, objectification becomes linguistic in intersubjectivity, reciprocity and dialogue. In the response of the other not only the does the Ego know the world, but also the other by itself. The function of the language is expressed in the object-to-object relationship, as a mediating example between the Ego and the world and mostly in the subjectsubject relationship, according to a dialogical model of knowledge. Language cannot be understood only as a poiesis (theoretical) process, but mainly as a praxis (practical) one. Objectification of the thought occurs only through language, more precisely when the word is returned, it resists the expressed Ego from the Buberian Other-Thou. The objectification of subjectivity is thus generated in dialogue, because in the dialogue where they meet, the I and You know each other, the objects take shape and the union of these objects constitutes the world. Objectivity in dialogue is always intersubjective and psychic subjectivity is transmitted only through the psychodynamic structures of personality and language organization. 


\section{Conclusions}

Language, communication and the human-social relationship are the main forms that interact in dependence on each other and at the same time that complement a particular social construction, which is analyzed and articulated in the psychodynamic organism. Language is no longer regarded simply as a system of sounds and a set of grammatical rules, but is studied in the subject-object relationship of the individual who uses it, thus becoming an instrument of communication and interaction in the social life.

The psycho-educational and psycho-linguistic contexts are significantly defined by terminology that defines the meaning of the discourse and affects the way interlocutors interact with each-other and in the social world. The Psychodynamic Diagnostic Manual as a Taxonomic form of a personality organization and a tendency of being towards the conscious and the unconscious, defines the object-subject boundary as nominative and dimensional form and content. Human being, after such a prototype identity, becomes part of the social life through communication not only as a subjective process, but also as a process that generates relationships between different psychic entities. Therefore, we can conclude that linguistic communication shapes individual lives as a psychological dimension and social life as a social dimension in its entirety.

\section{Acknowledgements}

This research did not receive any specific grant from funding agencies in the public commercial, or not-for-profit sectors.

The authors declare no competing interests.

\section{References}

Blatt, S. J., \& Luyten, P. (2009) Psychopathology: Two polarities of experience across the life span, Development and Psychopathology, 21, 793-814.

Blatt, S. J., \& Shichman, S. (1983). Two primary configurations of psychopathology. Psychoanalysis and Contemporary Thought, 6, 187-254.

Blatt, S. J., Stayner, D., Auerbach, J. S., \& Behrends, R. S. (1996). Change in object and self-representation in long term, intensive, inpatient treatment of seriously disturbed adolescents and young adults. Psychiatry, 59, 82-107.

Caligor, E., \& Clarkin, J. F. (2010). An object relations model of personality and personality pathology. In J. F. Clarkin, P. Fonagy \& G. O. Gabbard (Eds.), Psychodynamic psychotherapy for personality disorders. A clinical handbook (pp. 3-35). Washington, DC: American Psychiatric Publishing.

Freud S. (1932). Introduzione alla psicoanalisi (nuova serie di lezioni). In Opere, Italian Ed., Vol. 11, Boringhieri, Torino 1979, pp.121-284, referred Freud 1920.

Gazzillo, F., Gordon, R. M., Lingiardi, V., Del Corno, F., Bornstein, R. F., \& McWilliams, N. (2014). Empirical research with Psychodynamic Diagnostic Prototype (PDP) and the Psychodiagnostic Chart (PDC): Towards PDM-2. National Meeting of American Psychoanalytic Association, New York, pp. 14-19.

Gecas, V., \& Burke, P. J. (1995). Self and identity. In Comparing psychological and sociological approaches to identity: Identity status, identity capital and the 
individualization process, Cote' E. J. \& Schwartz J. S., Journal of Adolescence, 2002, 25, 572586.

Heidegger, M. (1976). Essere e Tempo. Eleventh edition, pp. 27, pp. 42, pp.128, pp. 182 (A cura di Pietro Chiodi) Longanesi \& C., Milano.

House, R. J. (1977). A 1976 theory of charismatic leadership. In J. G. Hunt \& L. L. Larsen (Eds.), Leadership: The cutting edge. Carbondale, IL: Southern Illinois University Press.

Humbolt, W. von. (2000). La diversità delle lingue, Roma-Bari, Laterza.

Kernberg, O. F., \& Caligor, E. L. (2005). A psychoanalytic theory of personality disorders. In J. F. Clarkin \& M. F. Lenzenweger (Eds.), Major theories of personality disorder (Second Edition, pp. 114-156). New York: Guilford.

Koeelen, J. A., Luyten, P., Eurelings Bontekoe, L. H., Diguer, L., Vermote, R., Lowyck, B., \& Bühring, M. E. (2012). The impact of level of personality organization on treatment response: A systematic review. Psychiatry, 75(4), 355-374.

Livesley, W. J. (2003-2004). Practical management of personality disorder. New York: Guilford Press.

Marcia, J. E. (1966). Development and validation of ego identity status. Journal of Personality and Social Psychology, 5, 551-558.

McWilliams, N. (2011). The psychodynamic diagnostic manual: An effort to compensate for the limitation sof descriptive psychiatric diagnosis. Journal of Personality Assessment, 93(2), 112-122. http://dx.doi.org/10.1080/00223891.2011.542709

Skodol, A. E., \& Bender, D. S. (2003). Why are women diagnosed borderline more than men? The Psychiatric Quarterly, 74(4), 349-360.

Safran, J. D., Muran, J. C., \& Eubanks Carter, C. (2011). Repairing alliance ruptures. Psychotherapy, 48(1), 80-87.

Safran, J. D., Muran, J. C., Samstag, L. W., \& Stevens, C. (2002). Repairing alliance ruptures II. In J. C. Norcross (Ed.), Psychotherapy relationships that work. New York, NY: Oxford University. 
S. Ibrahimi et al. - Dynamic Psycho-Linguistics: Impact of the Social Interaction...

C O A $\mathrm{s}$ 